\title{
Quantitative Evaluation of Soil Functions: Potential and State
}

\author{
Hans-Jörg Vogel ${ }^{1 *}$, Einar Eberhardt ${ }^{2}$, Uwe Franko ${ }^{1}$, Birgit Lang ${ }^{3}$, Mareike Ließ ${ }^{1}$, \\ Ulrich Weller ${ }^{1}$, Martin Wiesmeier ${ }^{4}$ and Ute Wollschläger ${ }^{1}$ \\ ${ }^{1}$ Helmholtz Centre for Environmental Research - UFZ, Leipzig, Germany, ${ }^{2}$ Federal Institute for Geosciences and Natural \\ Resources (BGR), Hanover, Germany, ${ }^{3}$ Senckenberg Museum of Natural History Görlitz, Görlitz, Germany, ${ }^{4}$ TUM School of \\ Life Sciences Weihenstephan, Technical University of Munich, Freising, Germany
}

\section{OPEN ACCESS}

Edited by:

Denis Angers,

Agriculture and Agri-Food Canada (AAFC), Canada

Reviewed by:

Christian Walter

Agrocampus Ouest, France Isabelle Cousin

INRA Centre Val de Loire, France

${ }^{*}$ Correspondence:

Hans-Jörg Vogel

hans-joerg.voge/@ufz.de

Specialty section:

This article was submitted to

Soil Processes,

a section of the journa

Frontiers in Environmental Science

Received: 02 April 2019 Accepted: 02 October 2019

Published: 22 October 2019

Citation:

Vogel H-J, Eberhardt E, Franko U,

Lang B, Ließ M, Weller U,

Wiesmeier $M$ and Wollschläger $U$ (2019) Quantitative Evaluation of Soil

Functions: Potential and State.

Front. Environ. Sci. 7:164

doi: 10.3389/fenvs.2019.00164
Soils play a key role for the functioning of terrestrial ecosystems. Thus, soils are essential for human society not only because they form the basis for the production of food. This has long been recognized, and during the last three decades the need to establish methods to evaluate the ability of soils to provide soil functions has moved toward the top of the agenda in soil science. Quantitative evaluation schemes are indispensable to adequately include soils into strategies to reach sustainable development targets. In this paper we build upon existing approaches and propose a concept to evaluate individual soil functions with respect to the soil's intrinsic potential in contrast to its actual state. This leads to a separation of indicator variables and allows for conclusions on the structure of appropriate models that are required to predict the dynamics of soil functions in response to external perturbation. This concept is demonstrated for the production function, carbon storage and water storage which are evaluated exemplarily for different plots of a long-term field experiment. It is discussed for nutrient cycling and habitat function, where evaluation schemes are still less obvious.

Keywords: soil functions, ecosystem services, soil indicators, modeling soil functions, soil evaluation

\section{INTRODUCTION}

The wish and need to evaluate soil functions is probably as old as agriculture. Until the 1990s, the focus was mainly on the evaluation of soil fertility and its suitability for growing different crops. Since then, the perspective on soil functions has increasingly moved beyond the agricultural potential reflecting the fact that soils are essential for the functioning of terrestrial ecosystems in many different ways (Doran and Parkin, 1994; Larson and Pierce, 1994; Blum, 2005) including climate control, water quantity and quality, nutrient cycling and being the habitat of an overwhelming biodiversity. These four additional aspects are critical for the earth system and are the subject of this paper along with the production function of soils, which is still of central importance for human societies. These $1+4$ soil functions also play an important role in realizing the UN Sustainable Development Goals related to food, water, climate health and biodiversity (Bouma and Montanarella, 2016; Keesstra et al., 2016). They are directly linked to soil ecosystem services which account for the immediate benefits that human societies derive from soils (Spangenberg et al., 2014; Hauck et al., 2013). Similarly, this was also addressed by the soil "natural capital" (Robinson et al., 2009; Costanza et al., 1997). Here we focus on soil functions as generated by interacting soil processes without any socioeconomic evaluation as implied by the notion of ecosystem services. Nonetheless, such an evaluation of soil functions is prerequisite for the derivation of ecosystem services. 
Being aware of the multifaceted nature of soil functions, their evaluation is increasingly summarized under the terms of soil health and soil quality (Doran and Parkin, 1994; Karlen et al., 1997; Kibblewhite et al., 2008), and the need to maintain soil multifunctionality has been emphasized by the term soil security (McBratney et al., 2014) in analogy to food security and water security. Today, how to actually quantify soil functions (Andrews et al., 2004; Schulte et al., 2014, 2015; Greiner et al., 2017; Bünemann et al., 2018) is a very active field of research. This is a formidable research challenge since soil functions are not welldefined soil properties measurable using some specific sensor but are considered to be integral properties emerging from a multitude of complex interactions between physical, chemical and biological processes in soil (Vogel et al., 2018). Hence, the evaluation of soil functions needs to be based on measurable soil properties, in the following referred to as soil attributes. Such a quantitative evaluation is not only highly required for decision makers including politicians, administrators and farmers to monitor positive or negative changes in soil functions. It is also a prerequisite for modeling the change of soil functions, which is essential to predict the (positive or negative) effects of external perturbations brought about mainly by agricultural soil management and not least climate change. This is one of today's most critical challenges in soil science.

In light of this general evidence and because of different motivations for soil function evaluation, there are different concepts available and applied. The main differences originate from four dimensions of consideration: (i) the target functions (i.e., which soil functions are in the focus and how are they defined), (ii) the general purpose of evaluation (i.e., are we interested in the actual state of a soil or its potential to fulfill some function), (iii) the spatial scale (i.e., evaluation of a local soil or mapping of soil functions across landscapes) and (iv) the target group (i.e., farmers, authorities, environmental agencies and the public). The common baseline of all concepts is that soil functions are estimated based on observable soil attributes used as indicators. Useful indicators are soil attributes that provide substantial information on soil functions such as soil bulk density or water capacity. The choice of indicators, however, depends on the context with respect to the four dimensions of consideration mentioned above: should they address the potential of soil to provide a distinct soil function or its current state in relation to its potential? Or should they be observable in the field, measurable in the lab or available through soil maps?

Recently, very valuable reviews on the various approaches have been provided by Bünemann et al. (2018) and Greiner et al. (2017) which will not be repeated here. A major conclusion of Bünemann et al. (2018) was that there are only a few approaches that provide clear interpretation schemes for the measured indicator values and that often clear conceptual or mechanistic relationships between indicators and soil functions are missing. With respect to modeling the dynamics of soil functions, such clear relationships are essential. The identification of soil attributes as valuable indicators should not only be based on pure statistical correlations. It should be based on our understanding of how soil functions are generated through the complex interactions of soil processes. Such an approach can open an avenue to model the dynamics of soil functions in response to external perturbations-be it agricultural management or climate change-using process-based models that focus on the dynamics of the soil attributes identified as valuable indicators (Vogel et al., 2018).

The aim of this paper is to synthesize available knowledge and concepts with the focus on mineral soils under agricultural use and humid temperate climate as typical for Central Europe. A crucial question is how to separate the evaluation of the soils' potential and the soils' actual state to fulfill soil functions. The discrepancy between both indicates the room for improving soil management for a specific soil with respect to its soil functions. Moreover, we treat the $1+4$ soil functions separately, which was recently suggested also by several authors (Bouma, 2014; Baveye et al., 2016; Bünemann et al., 2018). In this way, tradeoffs between soil functions can become visible, and the fact that different soils provide different contributions to the ensemble of soil functions is accounted for. This finally allows the development of soil- and site-specific management options. The evaluation of individual soil functions might be integrated under the roof of soil quality or soil health. However, we agree with Sojka and Upchurch (1999) that a general soil quality index entails a substantial loss of information. Evaluating the different soil functions separately allows for multicriterial optimizations of soil management strategies.

In the following, we first suggest a general concept of how to separate between the intrinsic potential of soil to fulfill the $1+4$ functions and the soil's actual state. For doing both, we follow the approach of dimensionless scoring functions as already introduced by others (Andrews et al., 2004; Mueller et al., 2007). These scoring functions need to integrate our current process understanding. They are ideally formulated on continuum scales in contrast to ordinal scales provided by scoring tables to better address dynamic changes. This concept is then demonstrated for a set of different soil functions, i.e., production, carbon storage and water storage, and we discuss how this could be extended to other soil functions, such as nutrient cycling and habitat for biological activity. Finally, we discuss how this could help in modeling soil functions and where to get the required data to make this concept operational.

\section{EVALUATION OF SOIL FUNCTIONS-SEPARATING POTENTIAL AND STATE}

When evaluating soil functions, the motivation is either to estimate the intrinsic potential of soil to fulfill various functions or to evaluate its actual state for doing so. The intrinsic potential of a soil is considered to be the maximum a soil can offer based on its inherent properties with respect to the various individual soil functions. This implies that all soil properties that can be affected by soil management within the limits of a good agricultural practice are in some optimum state. This intrinsic potential needs to be distinguished from the soils' actual state since the analysis has to be based on different soil attributes depending on these two different perspectives as we will explain in the following. 
The evaluation of the soils intrinsic potential should be related to inherent soil properties and site conditions (i.e., texture, mineralogy, soil depth, climate) since all that can be affected by soil management is only relevant for reaching this potential and, thus, cannot be part of its definition. For example, a silty loam soil from Loess has the potential to produce much higher yields as compared to a sandy soil even if the silty loam might perform as badly as the sandy soil due to insufficient management. Hence, when evaluating the potential of soil, we implicitly assume that all soil attributes that can be affected by soil management (e.g., bulk density, $\mathrm{pH}$, organic matter content) are in some optimum state. This is in fact an intuitive assumption for the evaluation of the soils potential being defined as, what could be achieved by some optimal soil management? In contrast, the evaluation of the actual state needs to be based on the manageable soil attributes, which was also referred to as dynamic soil quality (Karlen et al., 2003). Indeed, the evaluation of the actual state of soil is currently the major focus of soil quality rating (Mueller et al., 2007) because of its practical meaning for local soil management by farmers. In principle, the actual state can be compared to the soils' potential to quantify the room for improvement for an individual soil with respect to the individual soil functions. It should be noted that climate may change as well and consequently also the intrinsic potential as defined here might change. However, in the context of evaluating soil functions in response to soil management we consider time scales of not more than a decade and we assume that climate is stable.

In Table 1, the set of soil and site attributes that we consider important and that are typically used to estimate the state and potential of the different soil functions are summarized. Thereby, we distinguish three different categories: those related to the local climate $(\mathrm{C})$, to inherent soil properties and site conditions (S) and soil attributes which are affected by soil management (M). The categories C and S are used to evaluate the soils' potential while the evaluation of the actual state is based on category M. For each soil function, the soil attributes that are typically used as indicator variables are marked by colored boxes. The distinction of inherent and manageable properties was also introduced by Dominati et al. (2010) to demonstrate which properties can be affected by external drivers. Here we use this distinction to separate soils' potential from their actual state. It might be astonishing that among the inherent soil properties that determine the soils' potential there are no biological factors, although we are well aware that the vast majority of soil processes are biologically driven. The reason for this is that the development of biological communities and their activities depend on the abiotic boundary conditions. This has been reflected by an in-depth discussion of the meaning of organisms in soil formation by Jenny (1941). Hence, biological processes are included in the evaluation of soils' potential only implicitly in that e.g., a silty loam textured soil under humid conditions provides substantial capacity to store water and organic matter so that a rich biological community can evolve to ensure soil structure stabilization and nutrient cycling.

A technical challenge is how to combine properties with very different physical units as listed in Table 1. This is required to come up with some suitable estimator for each soil function.
To do so, we build upon the concept of scoring functions for individual soil attributes or suitable combinations of them. This is common practice in soil quality rating (Karlen et al., 2003; Mueller et al., 2007; Moebius-Clune, 2017). The basic idea is that observable soil attributes which are used to build indicators have some optimum range where the considered soil function is not impaired, while there are critical threshold values beyond which the soil functions start to be compromised. This can be expressed by dimensionless scoring functions that take values, e.g., between zero and unity, depending on the indicator value. Such scoring functions are required since the renormalization of the indicator values to a dimensionless scale allows the combination of different qualities of indicators. Moreover, if these scoring functions are continuous in contrast to ordinal scales based on lookup tables, this allows researchers to better evaluate dynamic changes and to better address uncertainties (Greiner et al., 2017).

As is clearly shown in Table 1, there are many attributes which are relevant for more than one soil function. In contrast to the approach proposed by Andrews et al. (2004), who combined the relevance of a given attribute for the various soil functions into one single scoring function, we define individual scoring functions for each indicator and for each individual soil function (i.e., for each colored box in Table 1). This means that attributes, which are relevant for different soil functions, are described by different scoring functions related to the specific soil function. For example, the scoring function of air capacity with respect to water storage might be different from that with respect to the production function. The separation of scoring functions for individual soil functions facilitates their definition and finally allows us to quantitatively address tradeoffs between soil functions. The challenge is to find and combine the optimal set of soil attributes which would allow us to effectively integrate our current knowledge of soil processes and how they affect the individual soil functions. Basically, the definition of the scoring functions integrates our actual knowledge on soil processes and how soil attributes affect the individual soil function. This knowledge is certainly incomplete. In this paper, we focus on the concept of how to apply and combine scoring functions while the detailed definition of these functions remains open for discussion and might be different for different crops and climatic regions.

To come up with a unique quantification of the individual soil functions, the rating with respect to the relevant attributes needs to be combined in a suitable way. This can be done at two levels. First, different soil attributes can be combined to generate a meaningful indicator. For example, the water capacity obtained from soil porosity along the soil profile can be added to the climatic water balance during the vegetation period to generate a meaningful indicator for the water deficit as critical for the production function. At the next level, the multiple dimensionless values of the various scoring functions need to be combined in a reasonable way. We suggest to use the harmonic mean in case the various indicators cannot compensate each other with respect to their impact on the given soil function. As demonstrated further below, this is typically the case. If there are compensatory effects, an arithmetic mean might be more appropriate. 
TABLE 1 | Inherent and manageable soil and site attributes which might be used as indicators to estimate the potential and the actual state of a soil to fulfill its functions.

\begin{tabular}{|c|c|c|c|c|c|c|c|c|c|c|c|c|c|c|c|c|c|c|c|}
\hline & & & & soil & \& & $\begin{array}{l}\text { nhe } \\
\text { site }\end{array}$ & $\begin{array}{l}\text { ren } \\
\text { con }\end{array}$ & $\begin{array}{l}\mathrm{t} \\
\text { diti }\end{array}$ & ons & & & & by & $\begin{array}{r}\text { a } \\
\text { soil }\end{array}$ & $\begin{array}{l}\text { affe } \\
\text { ma }\end{array}$ & $\begin{array}{l}\text { ctec } \\
\text { nag }\end{array}$ & $\begin{array}{l}\text { d } \\
\text { eme }\end{array}$ & & \\
\hline & & hyd & & & site & & & 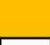 & soil & & & & phy & sics & & che & em. & & iol. \\
\hline & 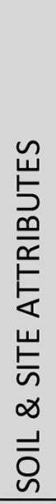 & 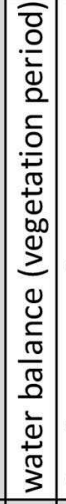 & 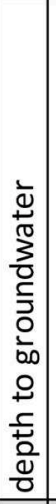 & 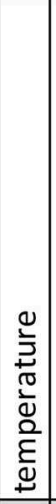 & 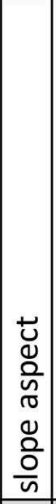 & 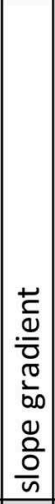 & 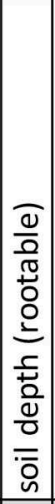 &  & 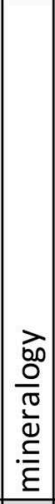 & O্তি & 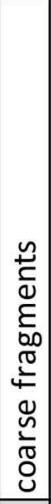 & 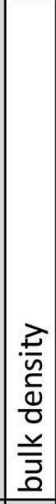 & 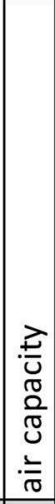 & 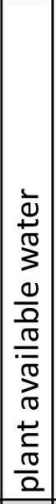 & 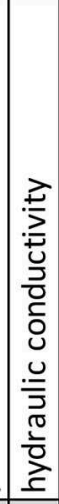 & 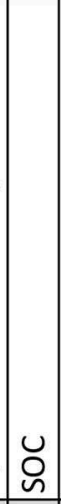 & I & 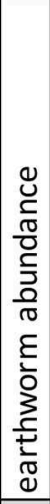 & $\begin{array}{l}\frac{3}{5} \\
\frac{2}{0} \\
\frac{3}{0} \\
0 \\
\frac{d}{0} \\
\frac{0}{n} \\
\frac{0}{n}\end{array}$ \\
\hline SOIL FUNCTIONS & & & & & & & & & & & & & & & & & & & \\
\hline Production (fertility) & & & & & & & & & & & & & & & & & & & \\
\hline Nutrient cycling - mobilizatio & & & & & & & & & & & & & & & & & & & \\
\hline Carbon storage & & & & & & & & & & & & & & & & $\mathrm{x}$ & & & \\
\hline Water storage \& filtering & & & & & & & & & & & & $x$ & & & & & & & \\
\hline Habitat for biological activity & & & & & & & & & & & & & & & & & & & $X$ \\
\hline
\end{tabular}

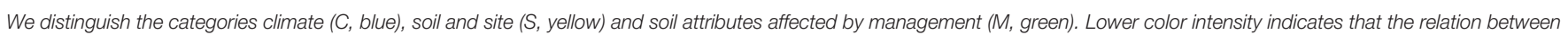
property and function is not yet well established. Boxes marked by X provide the most direct measure for the corresponding function state.

In the following we demonstrate this concept for the evaluation of the potential and actual state of soil with respect to the production function, carbon storage and water storage. The proposed scoring functions are introduced to demonstrate the concept, being aware that they might require adaptation for different crops. For other soil functions, where the state of knowledge on suitable evaluation concepts is even more vague (e.g., nutrient cycling and habitat for biological activity), we restrict the discussion to the current understanding of suitable indicators and how they could be quantified without suggesting specific scoring functions.

\section{EVALUATION OF SOIL FUNCTIONS-EXAMPLES}

\subsection{Production Function}

\subsubsection{Potential}

The evaluation of the soils' potential to produce biomass has been on the agenda of soil science for centuries. A powerful and frequently applied approach in Germany today is the Soil Quality Rating (SQR) (Mueller et al., 2007). This approach uses scoring tables at ordinal scales for the combination of selected soil attributes and is in principle equivalent to our approach based on continuous scoring functions. Evidently, the production of biomass depends on the grown crop. Like for most rating systems, we refer to wheat as an indicator crop and a site-specific climate. To evaluate the soils' potential for biomass production, we need to define an indicator $I_{\text {prod }}$ as a function of the inherent soil properties and site conditions, and we propose the following general form:

$$
I_{\text {prod }}=f\left(I_{\text {soil }}, I_{\text {water }}, I_{\text {energy }}\right)
$$

where $I_{\text {prod }}$ is a function of water availability depending on the local water deficit, $I_{\text {water }}\left(W_{\text {def }}\right)$ and the capacity to provide rooting space for the exchange of water and nutrients, which is a function of soil texture $I_{\text {soil }}$ (texture). The supply of energy is a third criterion $I_{\text {energy, }}$, depending on photosynthetic active radiation, which is further modified by temperature and the length of the frost-free period. Together, this determines the intensity of physiologic processes. For our indicator plant wheat, it is less limiting under conditions in central Europe, whereas it is crucial for other crops (as e.g., wine). This is why we only focus on the first two criteria in the following.

The local water deficit is obtained from the climatic water balance

$$
W_{\mathrm{bal}}=P-E T_{\mathrm{pot}}
$$

during the vegetation period (March - August) with $P$ being the cumulative precipitation and $E T_{\text {pot }}$ the potential evapotranspiration (Allen et al., 1998). This is added to the plant available water capacity estimated from soil texture, $A W C_{\text {texture }}$ [vol \%], of the soil in the upper $100 \mathrm{~cm}$. The soil profile can be composed of different soil horizons having different vertical extensions $d_{i}[\mathrm{~mm}]$ and different soil textures, so that the 
water deficit is calculated as:

$$
W_{\mathrm{def}}=\sum_{i} A W C_{\text {texture }} d_{i}+W_{\mathrm{bal}}
$$

This approach implicitly assumes that the soil is at field capacity in spring. It requires estimating field capacity from soil texture assuming some optimum state of the soil attributes in category $\mathrm{M}$ as e.g., bulk density. To do so, we refer to pedotransfer functions as proposed by the German soil mapping guideline (Ad-hocArbeitsgruppe Boden, 2005) assuming a bulk density of $1.3 \mathrm{~g} / \mathrm{cm}^{3}$ in the topsoil and $1.5 \mathrm{~g} / \mathrm{cm}^{3}$ in the subsoil. The scoring function for water availability is defined as a partial linear function in which the threshold for the critical water deficit where yields are expected to decrease is chosen to be $0 \mathrm{~mm}$ and a lower threshold of $-200 \mathrm{~mm}$, below which no substantial yield can be expected anymore. This approach can be applied for soils with deep groundwater level where capillary rise is negligible. It is illustrated in Figure 1.

The potential of soil to provide rooting space for plants for the uptake of water and nutrients, $I_{\text {soil }}$, is expressed as a function of soil texture. This is also done in the SQR approach (Mueller et al., 2007) where soil texture is segmented into five classes which are rated by different scores. We follow a similar approach but on a continuum scale. It is based on the understanding that both high sand contents and high clay contents diminish soil fertility. For sand, this is due to limited supply and buffer capacity for nutrients and for clay, due to limited accessibility for plant roots and reduced water availability. Additionally, we account for the volume fraction of stones $V_{s}$. Combining scoring functions for sand and clay (Figure 2, right) leads to

$$
I_{\text {soil }}=\sum_{i} I_{\text {texture }}\left(1-V_{s, i}\right) \omega_{i} \mid I_{\text {texture }}=\bar{x}_{\text {harm }}\left(I_{\text {sand }}, I_{\text {clay }}\right)
$$

as a dimensionless indicator for soil fertility based on the substrate (i.e., texture) as illustrated in Figure 2. The results for different horizons are summed up while the different horizons are weighed by the assumed depth distribution of roots described by $\omega_{i}$ with $\sum_{d_{i}} \omega_{i}=1$ and $\omega_{i}=0$ if the horizon is not rootable due to water logging or limited depth of the soil profile. In this example an exponential decline with depth was assumed as typical for cereals.

Finally, we end up with the evaluation of the soil's potential for biomass production by combining the indicators for water availability and soil substrate by calculating the harmonic mean (since both aspects can hardly compensate each other).

$$
I_{\text {prod }}=\bar{x}_{\text {harm }}\left(I_{\text {water }}, I_{\text {soil }}\right)
$$

\subsubsection{Actual State}

For the evaluation of the actual state, all the actually observable soil attributes of category $\mathrm{M}$ that are deemed to be relevant need to be addressed (Table 1). In principle, all of them are observable and measurable. For the production function we suggest the following attributes: $\mathrm{pH}$, SOC, bulk density and air capacity. The individual scoring functions should reflect if the optimum states depend on other soil properties. For example, the optimum
SOC content depends on soil texture since coarse textured soils have a reduced capacity for stabilizing soil carbon. This can be accounted for by evaluating the clay/SOC ratio which was found by Johannes et al. (2017) to be optimal in terms of soil structural properties below a value of 8 while it becomes critical above a value of 13 in cropland soils of Western Switzerland. Considering the yields in long-term field experiments in Eastern Germany (unpublished data), we shifted these thresholds toward slightly higher values (10 and 18). They can be considered in the corresponding scoring function as illustrated in Figure $\mathbf{3}$ where other scoring functions are plotted as well.

The scoring functions provide indicator values for each individual soil attribute based on thresholds defined for optimal and critical states. These thresholds might be adapted for different crops. The example given in Figure $\mathbf{3}$ is assumed to be appropriate for wheat. The threshold values delimiting the range of optimal values with respect to the individual soil attributes are given on the individual $\mathrm{x}$-axis in Figure 3. For air capacity we assume a step function at 1.0 vol\% assuming that for higher values the soil is sufficiently aerated while this reduces abruptly below this value. The minimum values of the scoring functions are assumed to be different for the different soil attributes. While plant growth below $\mathrm{pH} 1$ is hardly possible $(\mathrm{min}=0.0)$, this is not the case for critical values of SOC. The minimum values given in Figure 3 are our suggestions for a silty loam soil and are not based on any rigorous analysis.

It should be noted that all threshold values provided in Figure 3 have no general validity in any way. They are plausible values to demonstrate the proposed concept and certainly need to be adapted for specific crops. But more generally, they can be easily adapted into our steadily improving understanding fed by ongoing research as documented by an enormous body of publications on the relation between soil attributes and soil functions. Thus, the scoring functions are a means for synthesizing the existing knowledge. They allow for including uncertainties in that the punctual kinks of the scoring function can be replaced by a fuzzy region which will directly translate to some uncertainty range for the evaluation of the result.

Finally, all indicators are combined to evaluate the actual state of a soil layer $i$ based on manageable soil attributes relative to the site-specific optimum value:

$$
\hat{I}_{\text {prod,i }}=\bar{x}_{\text {harm }}\left(I_{\mathrm{pH}}, I_{\text {Clay } / \mathrm{SOC}}, I_{\rho_{b}}, I_{\mathrm{AC}}, \ldots\right)
$$

The dots in Equation (6) indicate that other attributes might be considered in addition. In this example, not all soil attributes that are deemed to be relevant according to Table 1 are considered. This is mainly because quantitative concepts are yet to be developed (topsoil structure, earthworm abundance, biodiversity).

The harmonic mean is defined such that its value tends toward zero if one of the elements is zero. The evaluation of the actual state of a soil profile is finally obtained by summation over the different horizons including a weighing function as introduced in Figure 2:

$$
\hat{I}_{\text {prod }}=\sum_{i} \hat{I}_{\text {prod,i }} \omega_{i}
$$



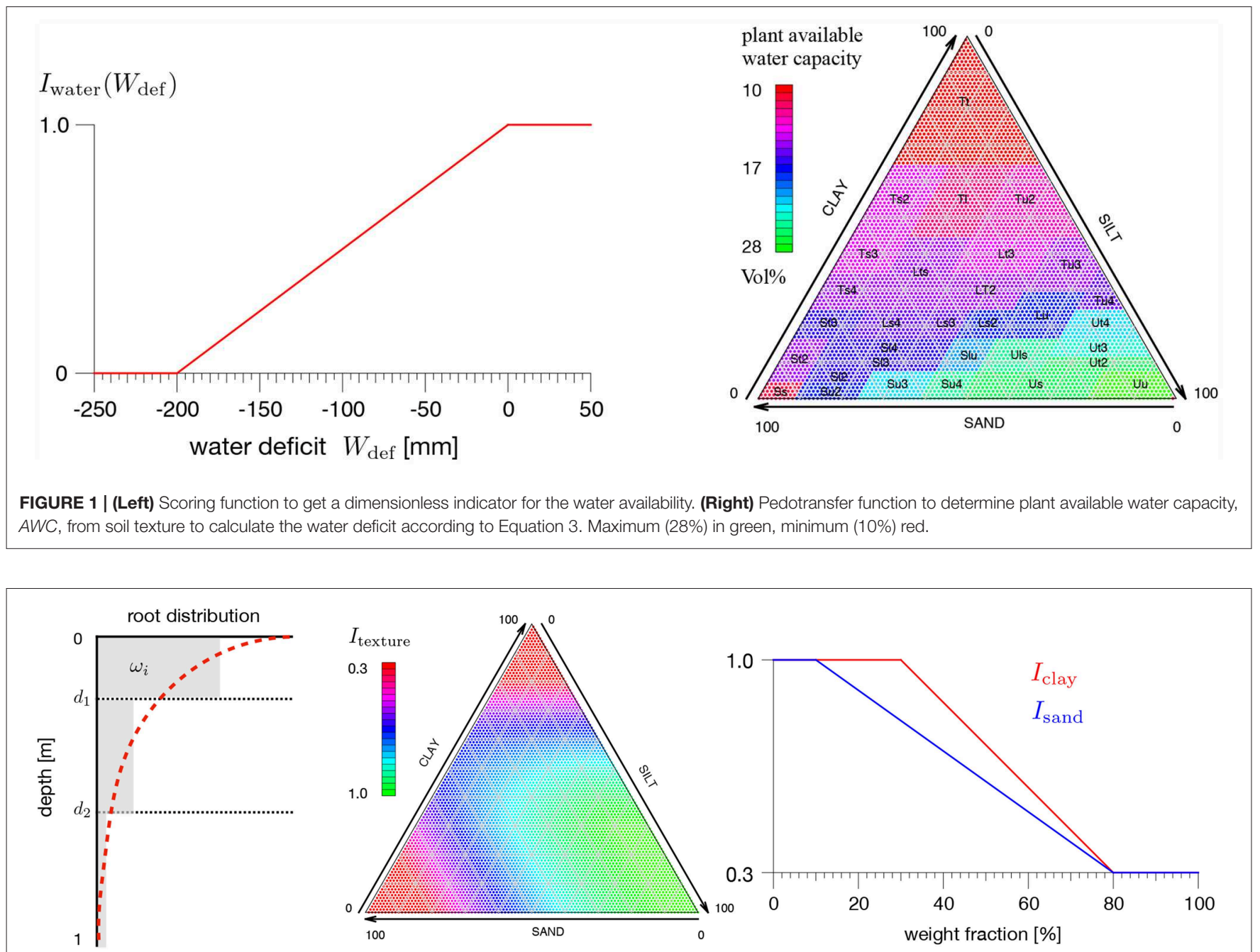

FIGURE 2 | Scoring functions for sand and clay content (Right) combined by their harmonic mean according to Equation (4) to get a dimensionless indicator for soil fertility based on soil texture (Middle, green is maximum) which is combined to an indicator for the entire soil profile by weighing the results for the different horizons based on the depth distribution of root length density (Left).

The Clay/SOC ratio is especially relevant for the topsoil, which is assumed to be well mixed by tillage and natural structure dynamics. It is ignored in the subsoil while attributes relevant for root growth and water uptake need to be considered there. The evaluation of the actual state, $\hat{I}_{\text {prod }}$, quantifies the degree of fulfillment of the soil's potential $I_{\text {prod }}$ (Equation 5) at a scale between 0 and 1 .

\subsection{Water Storage}

\subsubsection{Potential}

The storage function for water is considered here as an important factor to retain precipitation water from fast transport toward groundwater and surface waters. The importance for plant production was considered in the context of the production function. Water storage is directly related to the available pore volume within the soil profile. Assuming an optimal bulk density of $1.3 \mathrm{~g} / \mathrm{cm}^{3}$ in the topsoil and $1.5 \mathrm{~g} / \mathrm{cm}^{3}$ in the subsoil, this pore volume can be estimated from soil texture along the soil profile. Following the approach of Danner et al. (2003), the large pores addressed by the air capacity contribute to water storage in flat areas while on slopes $>9 \%$ this pore volume is assumed to be drained very fast. Hence, the potential for water storage in soil (upper $100 \mathrm{~cm}$ ) is estimated by

$$
I_{\text {water storage }}=\frac{1}{W C_{\max }} \sum_{i}\left(F C_{\text {texture }}+a A C_{\text {texture }}\right)\left(1-V_{s}\right) d_{i}
$$

where $F C_{\text {texture }}[\mathrm{vol} \%]$ and $A C_{\text {texture }}$ [vol \%] are field capacity and air capacity at optimal pore volume, respectively, as estimated from soil texture (Figure 4) for $i$ soil layers and $a=1-S / 9$ for slopes $S[\%]<9 \%$ and $a=0$ for steeper slopes where the term including air capacity is omitted. $V_{s}$ [vol \%] is the volumetric fraction of stones. $W C_{\max }=450 \mathrm{~mm}$ is the maximum water capacity of a $1 \mathrm{~m}$ deep soil profile as referred to a loamy clay soil. 


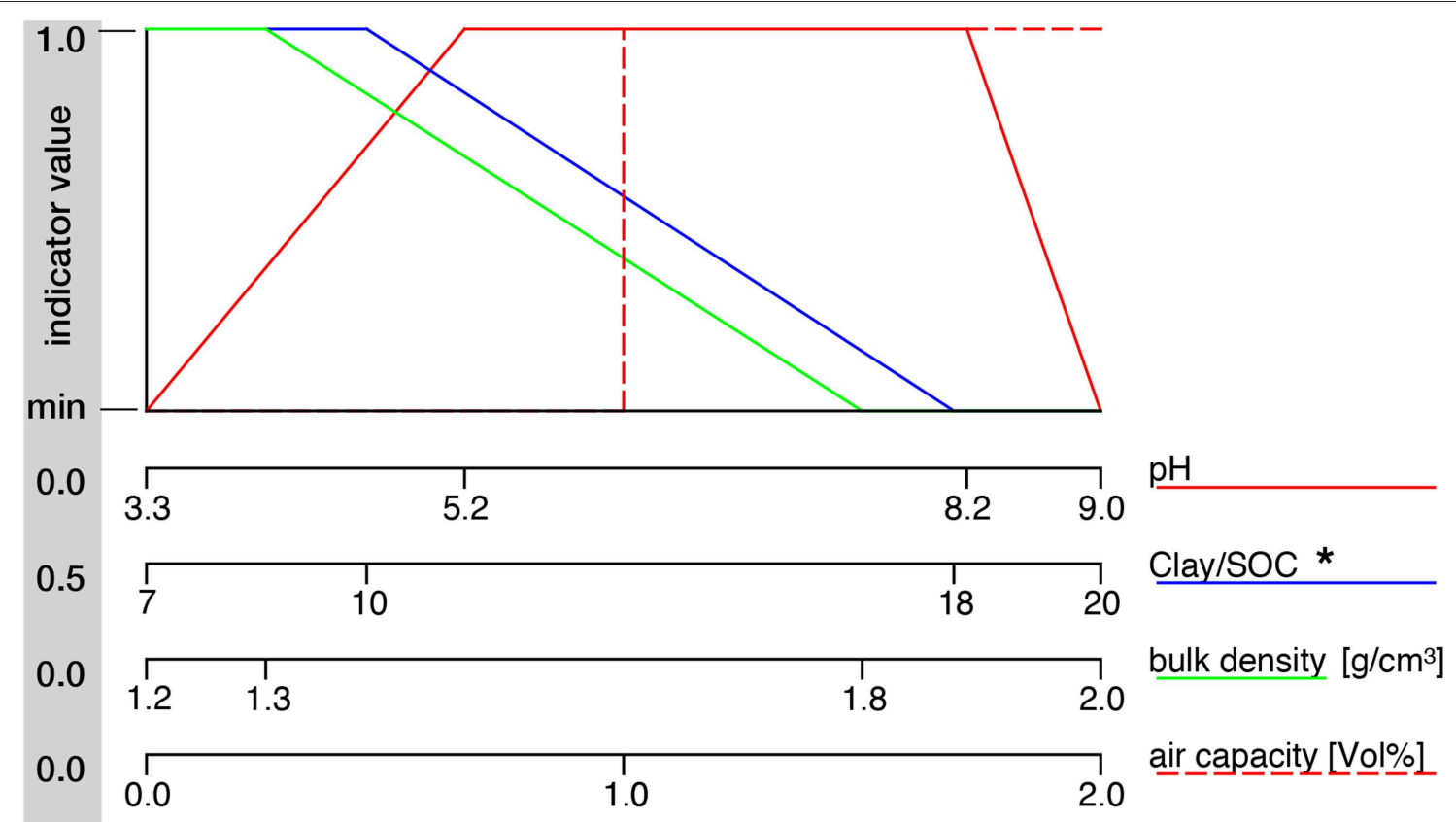

FIGURE 3 | Possible scoring functions for manageable soil attributes to evaluate the actual state with respect to the production function. The Clay/SOC ratio marked by * is only evaluated in the topsoil. Threshold values for optimal and critical states are given on the individual $\mathrm{x}$-axis.
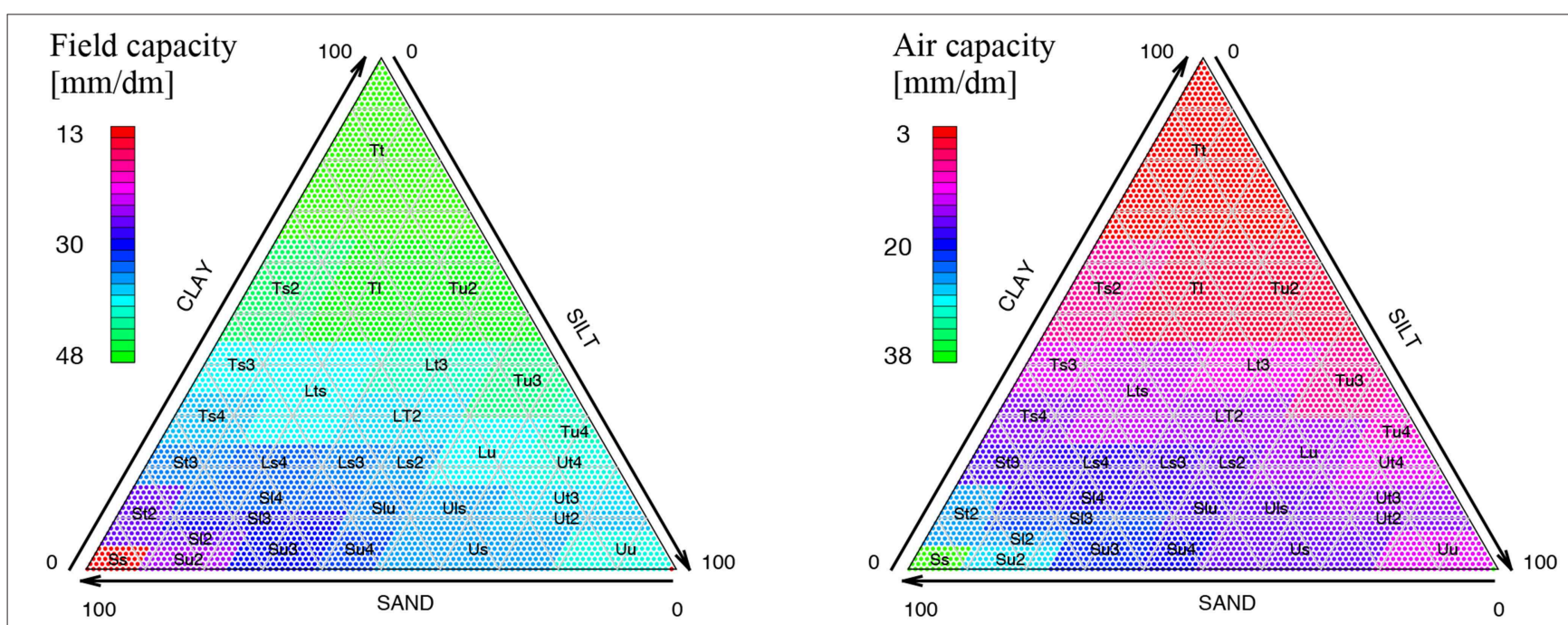

FIGURE 4 | Field capacity (Left) and air capacity (Right) as derived from soil textural classes according to the German soil classification (Ad-hoc-Arbeitsgruppe Boden, 2005). The range of values from low (red) to high (green) assuming a bulk density of $1.3 \mathrm{~g} / \mathrm{cm}^{3}$ is given in brackets.

\subsubsection{Actual State}

The estimation of the storage potential (Equation 8 ) implicitly assumes that field capacity is in some optimum state depending on soil texture. The actual state might be altered by soil compaction and can be measured directly by soil porosity. The degree of fulfillment of the water storage function is then provided by

$$
\hat{I}_{\text {water storage }}=\frac{1}{\sum_{i} d_{i}} \sum_{i} \frac{F C_{\text {measured }, i}+a A C_{\text {measured }, i}}{F C_{\text {texture }}+a A C_{\text {texture }}} d_{i}
$$

in analogy to Equation (8) assuming a constant fraction of stones.

\subsection{Carbon Storage}

\subsubsection{Potential}

The potential of soils to store carbon depends on a variety of pedogenic, biological, topographic and climatic properties. In a recent review, the suitability of various factors (clay mineralogy, specific surface area, metal oxides, $\mathrm{Ca}$ and $\mathrm{Mg}$ cations, microorganisms, soil fauna, aggregation, texture, soil type, natural vegetation, land use and management, topography, 
parent material and climate) as indicators for actual and potential carbon storage in temperate agricultural soils was assessed with regard to different spatial scales (Wiesmeier et al., 2019).

For an estimation of the SOC storage potential, different approaches have been proposed related to the $\mathrm{C}$ saturation of the fine mineral fraction (Hassink, 1997) as well as "datadriven" and "model-driven" approaches (Barré et al., 2017; Chen et al., 2019a). We follow the $\mathrm{C}$ saturation approach that was frequently used to quantify the potential of (agricultural) soils to store carbon (Angers et al., 2011; Chan, 2001; Carter et al., 2003; Conant et al., 2003; Sparrow et al., 2006; Stewart et al., 2008; Zhao et al., 2006; Wiesmeier et al., 2014a; Chen et al., 2018, 2019b). This approach is based on the observation that the amount of SOC in most soils in temperate environments is strongly correlated with silt/clay contents (Arrouays et al., 2006; Hassink, 1997), pointing toward the importance of organomineral associations as quantitatively the most important SOC stabilization mechanism (von Lützow et al., 2006). The stabilizing capacity of silt and clay-sized particles was used to delineate regression models for the estimation of the SOC storage potential related to the fine mineral fraction of different soils, land uses and climatic regions (Hassink, 1997; Six et al., 2002; Zhao et al., 2006; Feng et al., 2013; Beare et al., 2014; Wiesmeier et al., 2015). As size thresholds for the fine mineral fraction, both 20 and $50 \mu \mathrm{m}$ were proposed. It is important to note that the $\mathrm{C}$ saturation approach only allows a quantification of the storage potential of $\mathrm{C}$ that is temporarily stabilized in the fine fraction. The amount of (labile) $\mathrm{C}$ in the coarse fraction which is controlled by actual $\mathrm{C}$ input cannot be quantified. However, given the fact that agriculturally used soils contain a relatively large proportion of stable $\mathrm{C}$, the C saturation approach can be regarded as a useful method to quantify the C storage potential (Chen et al., 2019b; Beare et al., 2014; Wiesmeier et al., 2014b). Among the different approaches, the specific regression models proposed by Six et al. (2002) for different land uses (cropland, grassland) and size ranges of the fine mineral fraction $(<20 \mu \mathrm{m},<50 \mu \mathrm{m})$ are most suitable for our approach. Following this approach, the $C$ storage potential of topsoils under cropland $\left(C_{p}\left[\mathrm{~kg} / \mathrm{m}^{2}\right]\right)$ can be calculated by

$$
C_{p}=(4.38+0.26 T) \rho_{b} d\left(1-V_{s}\right)
$$

or

$$
C_{p}=(7.18+0.20 T) \rho_{b} d\left(1-V_{s}\right)
$$

where $T$ is the percentage of particles $<20 \mu \mathrm{m}$ [\%] in Equation (10) and of particles $<50 \mu \mathrm{m}$ in Equation (11). The expression in the first brackets is the estimated C content $[\mathrm{mg} / \mathrm{g}]$, $\rho_{b}$ is the bulk density $\left[\mathrm{g} / \mathrm{cm}^{3}\right], d$ is the thickness of the topsoil [dm] and $V_{s}$ is the volume of rock fragments $>2 \mathrm{~mm}[\%]$. As the content of particles $<20 \mu \mathrm{m}$ (medium silt, fine silt and clay) is rarely reported in studies (although the information is available in most common methods for soil texture determination), the respective equations related to particles $<50 \mu \mathrm{m}$ (total silt and clay content) may be used alternatively-taking into account the different classification approaches for silt. Following the C saturation approach, the potential of soil to store stabilized carbon is a direct function of soil texture. If the fraction of

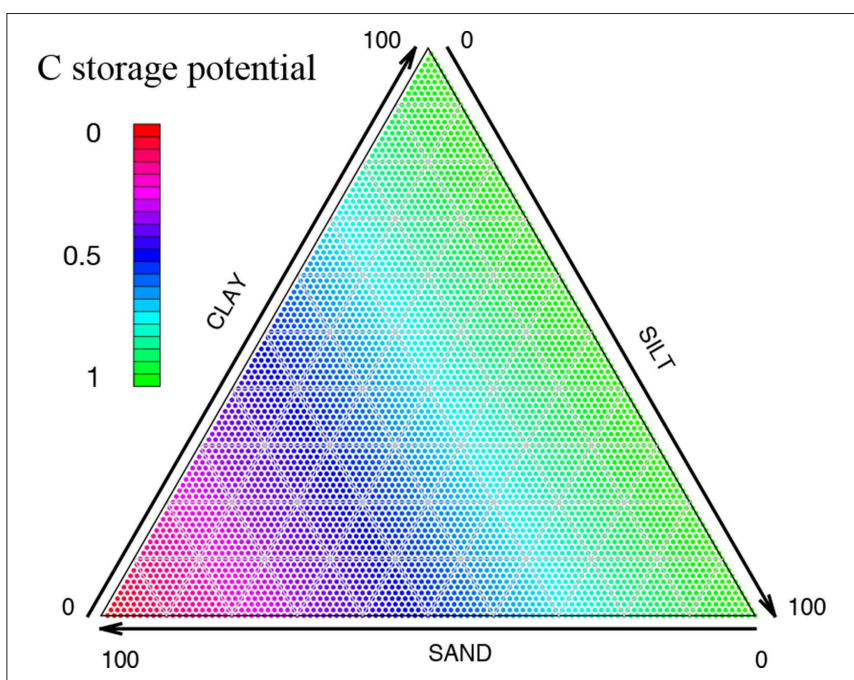

FIGURE 5 | Storage potential/soc for organic carbon is a direct function of soil texture according to Equation (12).

particles $<20 \mu \mathrm{m}$ is considered, we relate the $C_{p}$ amount to the theoretical maximum of 30.38 for $T=100$ (Equation 10) and calculate the storage potential $I_{\mathrm{SOC}}$ as

$$
I_{\mathrm{SOC}}=\frac{1}{30.38}(4.38+0.26 T)\left(1-V_{s}\right)
$$

as illustrated in Figure 5.

Although the $\mathrm{C}$ saturation approach is a promising method to estimate the $\mathrm{C}$ storage capacity of agricultural soils, there are several limitations. To date, only $\mathrm{C}$ saturation of topsoils was studied, neglecting the fact that subsoils store considerable amounts of $\mathrm{C}$ and may contain a huge $\mathrm{C}$ storage potential (Lal, 2018; Rumpel and Kögel-Knabner, 2011). Studies are needed that determine the potential $\mathrm{C}$ saturation of subsoils under different land uses in a comprehensive way in order to derive a reliable estimate of the $\mathrm{C}$ storage capacity of subsoils. The method was further criticized as it does not allow a quantification of the total SOC storage potential but only refers to the stable $\mathrm{C}$ in the fine mineral fraction (Barré et al., 2017; Chen et al., 2018). Despite these limitations, the $\mathrm{C}$ saturation concept seems to be suitable to estimate the $\mathrm{C}$ storage potential at the plot scale with a limited data set of widely available soil properties.

\subsubsection{Actual State}

The actual state of SOC can be quantified directly using

$$
C_{s}=\sum_{i} \operatorname{SOC}_{i} \rho_{b, i} d_{i}\left(1-V_{s, i}\right)
$$

where $C_{s}\left[\mathrm{~kg} / \mathrm{m}^{2}\right]$ is the stock of soil organic carbon, $\mathrm{SOC}_{i}[\mathrm{mg} / \mathrm{g}$ soil] its concentration in soil horizon $i, \rho_{b, i}\left[\mathrm{~g} / \mathrm{cm}^{3}\right]$ is the bulk density, $d_{i}[\mathrm{dm}]$ is the thickness of the horizon and $V_{s, i}$ is the volume of rock fragments $>2 \mathrm{~mm}[\%]$. This includes the stable and the labile $\mathrm{C}$ fractions. As the quantification of the stable fraction requires laborious and time-consuming 
soil fractionation, the amount of stable $\mathrm{C}$ can be estimated by assuming it is a constant proportion of total SOC $\left(C_{s}\right)$. For temperate cropland soils, a proportion of stable $\mathrm{C}$ of approximately $80 \%$ of total SOC was determined (Chen et al., 2019b; Di et al., 2017; Wiesmeier et al., 2014b). The evaluation of the actual state of $\mathrm{C}$ storage can thus be calculated by

$$
\hat{I}_{\text {SOC }}=\frac{0.8 C_{s}}{C_{p}}
$$

to quantify the degree of fulfillment of the soil's potential to store organic carbon.

\subsection{Nutrient Cycling}

The provision of nutrients for plants and to fuel the ensemble of biological processes in soil is one of the key functions of soil. This is why "nutrient cycling" is almost always addressed explicitly in today's approaches of soil function evaluation (Greiner et al., 2017; Bünemann et al., 2018). The most important macronutrients are $\mathrm{N}, \mathrm{P}$, and $\mathrm{S}$ together with the cations $\mathrm{K}$, $\mathrm{Ca}$, and $\mathrm{Mg}$. The absolute quantity of nutrients in arable soil is typically adjusted by fertilization, and the uptake by plants and the immobilization through biological processes and sorption are highly dynamic processes. Consequently, the actual concentration of available nutrients is highly variable and, thus, this concentration is difficult to interpret as an indicator for the processes of nutrient cycling. We consider this function to be mainly related to two different aspects: (i) the capacity of soil to provide nutrients from the mineral and organic soil resources in available form and (ii) the capacity to store mobile nutrients within the root zone to avoid losses by leaching and gaseous emissions.

The first aspect relates to the nutrient mobilization capacity, the second to the nutrient buffering capacity. Both aspects depend more on inherent soil properties such as texture, mineral composition and temperature as well as dynamic soil properties such as soil organic matter, soil water capacity, aeration and $\mathrm{pH}$ rather than on the actual concentration of nutrients in the soil solution. This is why nutrient concentrations are not part of the list of indicators in Table $\mathbf{1 .}$

The processes responsible for nutrient mobilization and buffering are rather different for the various nutrients and cannot be described adequately by some general function or set of indicators. For example N, P, and S are mainly recycled from soil organic matter by the activity of various soil organisms, and the buffer capacity for these nutrients is mainly provided by the dynamic mass of the soil biome. In contrast, cations are released from the mineral phases along with slow weathering processes, and the buffer capacity is brought about by the capacity of sorption sites expressed by the cation exchange capacity (CEC), which is closely related to soil texture and organic matter.

An evaluation of nutrient cycling, on one hand, needs to address mineralization of soil organic matter and buffering of nutrients by soil organisms. Both features can be directly linked to the overall potential of soil to allow for biological activity as a lumped effective description. This implicitly assumes that the overwhelming diversity of soil biota provides the required functional traits for mineralization and the dynamic adaption in terms of active biomass. On the other hand, such an evaluation needs to include the extent of mineral surfaces acting as sorption sites.

All these features are implicitly included in the evaluation of the production function described above. Hence, we suggest that the soil's potential for nutrient cycling is approximated by $I_{\text {prod }}$ (Equation 5) considering soil texture as an indicator for the quality of soil as habitat for organisms and the availability of water. In analogy, the soil's actual state in terms of nutrient cycling can be approximated by $\hat{I}_{\text {prod }}$ as a function of $\mathrm{pH}$, organic carbon, soil bulk density and soil air capacity. This accounts for the general understanding that soil fertility (i.e., the production function) and nutrient cycling are two sides of the same coin and hardly separable.

\subsection{Habitat for Biological Activity}

Soil biota and their interactions are both directly and indirectly responsible for delivering a number of soil functions, thus, the provision of a habitat for biological activity is an important prerequisite for other soil functions. We here perceive the function "habitat for biological activity" as the provision of a species (gene) pool that can buffer ecosystem functions against species extinction (Hooper et al., 2005) and assume that systems with low species diversity contain fewer species within each functional group, and are thus more susceptible to losing entire ecosystem functions (Bardgett and Van Der Putten, 2014). Hence, the habitat function addresses the diversity in terms of species and functions, which is in contrast to the biological activity in terms of mineralization rate and nutrient buffering as discussed in the previous section.

\subsubsection{Potential}

As with the other soil functions, the soil's potential to harbor a diverse community of soil biota depends on inherent soil properties and site conditions listed in Table 1. Soil organisms are affected by the local climate in terms of the local moisture and temperature regime. This effect is both direct (e.g., on the physiology) and indirect (e.g., by changes in carbon resources) (Turbé et al., 2010). Latitudinal and altitudinal gradients of biodiversity with increasing species richness toward the equator and decreasing soil biodiversity with altitude are shown for some soil faunal groups (Decaëns, 2010). Furthermore, soil texture affects soil biodiversity with e.g., lower earthworm or microbial biomasses in sandy soils (Turbé et al., 2010; Griffiths et al., 2016; Aksoy et al., 2017).

\subsubsection{Actual State}

Land use and soil management practices are known to affect soil faunal communities with different responses depending on taxonomic or functional groups (Sánchez-Moreno et al., 2011; van Capelle et al., 2012; Cluzeau et al., 2012). Agricultural intensification was shown to decrease functional diversity or even result in the loss of entire functional groups (Tsiafouli et al., 2015). Abundance, species richness and diversity of soil biota are affected by $\mathrm{pH}$, bulk density and SOC content (see Table 1). Species abundance and diversity can furthermore be affected by 
vegetation composition and diversity in grasslands (Sabais et al., 2011) or the type of crop species in agriculture (Scheunemann et al., 2015).

To evaluate the actual state of the habitat for biological activity, soil biodiversity can be directly measured. Measures of soil biodiversity include species richness, diversity indices (e.g., shannon index, simpson index), the presence of keystone species and functional diversity. This requires extensive fieldwork and is done by a number of national monitoring programs, but methods vary and standardized indicators are not available (see Pulleman et al., 2012 for an overview of European approaches). To standardize indicators for soil biodiversity monitoring across Europe, the Envasso (ENVironmental ASsessment of Soil for mOnitoring) project proposed a minimum set of indicators comprising (a) earthworm diversity, abundance and biomass (or enchytraeids if earthworms are absent), (b) springtail diversity and abundance and c) microbial respiration (Huber et al., 2008; Bispo et al., 2009). Additional measurements of the diversity of macrofauna, mites, nematodes and microflora, as well as microflora activity, are recommended (Huber et al., 2008). The prediction and mapping of soil biodiversity based on inherent and manageable soil and site attributes is considered as currently not feasible by the LANDMARK project due to the lack of indicators and specific reference values with respect to soil types, climate and land use, as well as models (Staes et al., 2018). However, there are some recent approaches to assess the actual state of the habitat for biological activity based on, e.g., geographic location, soil $\mathrm{pH}$, soil organic matter content, texture, land use and climate (Aksoy et al., 2017; Rutgers et al., 2016, 2019) or by using the QBS index (Qualità Biologica del Suolo), which assumes that the habitat function of soils is reflected by a higher number of microarthropods well adapted to soil habitats (Parisi et al., 2005), in combination with SOC content and bulk density (Calzolari et al., 2016).

According to our approach, comprehensive data on soil biodiversity in dependence of site-specific characteristics are needed to develop appropriate models and scoring functions relating soil properties to biodiversity measures. As a basis for model development, databases such as the soil zoological information system Edaphobase (www.edaphobase.org) (Burkhardt et al., 2014), which links data from collections, scientific literature and reports to soil and site conditions, or the Land Use/Cover Area frame statistical Survey Soil (LUCAS Soil), which included soil biodiversity in its 2018 soil sampling campaign (Orgiazzi et al., 2018), can be used.

\section{EXAMPLE FROM A LONG-TERM FIELD EXPERIMENT}

As an example to demonstrate our approach, we evaluate the production function, the $\mathrm{C}$ storage function and the water storage function for a Chernozem soil at the agricultural long-term field experiment in Bad Lauchstädt $\left(51^{\circ} 23^{\prime} 24.93^{\prime \prime} \mathrm{N}, 11^{\circ} 52^{\prime} 49.93^{\prime \prime} \mathrm{E}\right)$. This soil from Loess deposits over glacial drift belongs to the most productive soils in Germany. The texture in the topsoil is silt loam with $22.2 \%$ clay, $72.2 \%$ silt (6.9\% fine, $23.3 \%$ medium,
$42 \%$ coarse) and $5.6 \%$ sand which corresponds to the class Ut 4 in German soil classification (Ad-hoc-Arbeitsgruppe Boden, 2005). The long-term field experiment with different levels of organic and mineral fertilizers has been running since 1902, and we use some of the experimental plots to evaluate the actual state of the soil with respect to a number of manageable soil attributes which have been measured in the past. The inherent soil and site characteristics together with the manageable soil attributes measured in 1 year (1998) for a selection of different experimental plots are given in Table 2.

\subsection{Production Function}

There is no limitation for soil productivity based on the silty loam texture (Figure 2) so that $I_{\text {soil }}=1$. Bad Lauchstädt is located in a relatively dry region of Germany with $8.9^{\circ} \mathrm{C}$ annual mean temperature and annual mean precipitation of $498 \mathrm{~mm}$. The climatic water balance during the growth period (March-August) according to Equation (2) is $228 \mathrm{~mm} 412 \mathrm{~mm}=-194 \mathrm{~mm}$ (5 years average for 2013-2017). Because of the high water capacity of $370 \mathrm{~mm}$, the water deficit (Equation 3) was positive $(176 \mathrm{~mm})$, meaning there is no water deficit, so that $I_{\text {water }}=1$. Hence, the soil's potential in terms of productivity was equal to unity and herewith maximal. However, during the exceptionally dry year of 2018, the precipitation from March to August was reduced to 40 $\mathrm{mm}, E T_{P}$ was increased to $435 \mathrm{~mm}$ and, consequently, the water balance became negative $(-25 \mathrm{~mm})$ so that $I_{\text {water }}=0.9$ according to Figure 1. In fact, the yield of wheat in 2018 was decreased to $75 \%$ as compared to the 5-year average before.

The evaluation of the actual state for the different experimental plots is restricted to the topsoil $(0-25 \mathrm{~cm})$ since measurements were available only for this layer. Bulk density is almost the same in all plots $\left(1.4 \mathrm{~g} / \mathrm{cm}^{3}\right)$, which is somewhat denser as compared to what was considered as optimum (1.3 $\mathrm{g} / \mathrm{cm}^{3}$ ). Thus, the corresponding scoring function (Figure 3) yields values for $I_{\rho_{b}}$ below unity. Because of the differences in fertilization, the plots differ in SOC content, and this is reflected by the scoring function (Figure 3) for the clay/SOC ratio. This indicator ranges from 15.1 in the non-fertilized plot to 9.5 in the fully fertilized plot (NPK /manure) so that the optimum value, $I_{\text {clay } / \mathrm{SOC}}=1$ is reached only for the latter but decreases according to the scoring function (Figure 3) to 0.68 for the non-fertilized plot. This suggests that the level of soil organic matter is considered to be a limiting factor for biomass production. The $\mathrm{pH}$ is within the optimum range for all plots so that $I_{p H}=1$.

Finally, the overall evaluation of the actual state for the different experimental plots is obtained by the harmonic mean according to Equation (6). The resulting values for $\hat{I}_{\text {prod }}$ as listed in Table 2 suggest that the fully fertilized plot is close to its potential. In the non-fertilized plot, $I_{\text {prod }}$ reaches $84 \%$, suggesting that the impact of SOC on crop yield is not very high. Actually, the wheat yield was only $35 \%$ of the fully fertilized plot. At first glance, this looks like a complete failure of our indicator. However, this discrepancy is due to the fact that the indicator assumes some "good agricultural practice" including the provisioning of nutrients according to the expected yield. The nitrogen level of soil, though highly important for yield, 
TABLE 2 | Inherent soil and site properties for the Chernozem in Bad Lauchstädt together with manageable soil attributes and related indicator values according to Figure $\mathbf{3}$ for four experimental plots which received different amounts of fertilizers (NPK/manure) over a period of more than 100 years.

\begin{tabular}{|c|c|c|c|c|c|c|c|c|c|c|c|c|c|c|c|c|}
\hline & \multirow[b]{3}{*}{ 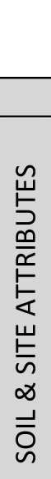 } & \multicolumn{5}{|c|}{$\begin{array}{c}\text { inherent soil \& site } \\
\text { conditions }\end{array}$} & \multicolumn{8}{|c|}{ affected by soil management } & \multirow[b]{3}{*}{ पू. } & \\
\hline & & \multirow[b]{2}{*}{ 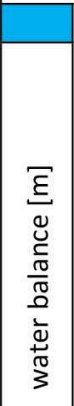 } & \multirow[b]{2}{*}{$\begin{array}{l}\frac{0}{2} \\
\frac{0}{0} \\
\frac{0}{n}\end{array}$} & \multirow[b]{2}{*}{ 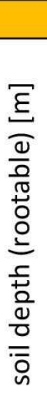 } & \multirow[b]{2}{*}{ 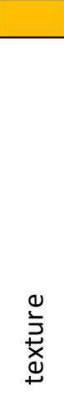 } & \multirow[b]{2}{*}{ 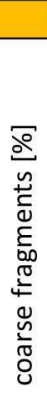 } & \multicolumn{3}{|c|}{ physics } & \multicolumn{5}{|c|}{ chemistry } & & \multirow[b]{2}{*}{ 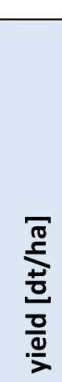 } \\
\hline & & & & & & & 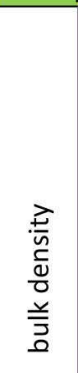 & $v^{2}$ & 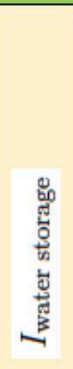 & $\begin{array}{l}\text { ঠo } \\
\text { o }\end{array}$ & 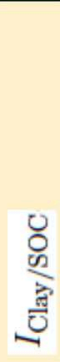 & $\begin{array}{l}\text { ๖ } \\
\text { W }\end{array}$ & $\frac{T}{2}$ & 票 & & \\
\hline \multicolumn{17}{|l|}{ SOIL FUNCTIONS } \\
\hline \multicolumn{17}{|l|}{ production (fertility) } \\
\hline \multicolumn{15}{|l|}{ C-pool } & & \\
\hline \multicolumn{17}{|l|}{ water storage } \\
\hline \multirow{5}{*}{ Bad Lauchstädt } & & 0.17 & 0 & $>1$ & Ut4 & 0 & & & & & & & & & & \\
\hline & \multicolumn{6}{|c|}{$0 / 0$} & 1.4 & 0.8 & 0.92 & 1.47 & 0.68 & 0.65 & 7.0 & 1 & 0.84 & 32.3 \\
\hline & \multicolumn{6}{|c|}{$\mathrm{NPK} / 0$} & 1.4 & 0.8 & 0.92 & 1.68 & 0.80 & 0.75 & 6.2 & 1 & 0.89 & 81.6 \\
\hline & \multicolumn{6}{|c|}{$0 /$ manure } & 1.41 & 0.78 & 0.91 & 2.14 & 0.98 & 0.95 & 6.8 & 1 & 0.93 & 71.2 \\
\hline & \multicolumn{6}{|c|}{ NPK/manure } & 1.39 & 0.82 & 0.93 & 2.33 & 1 & 1.04 & 6.2 & 1 & 0.95 & 91.3 \\
\hline
\end{tabular}

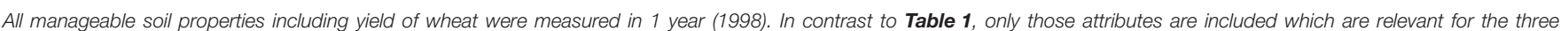
considered functions and which were available.

is not considered in the evaluation of the soils' status because it is highly dynamic and can easily be adjusted by fertilization. On the non-fertilized plot, no fertilizer was applied so that the missing nitrogen especially led to a much more dramatic decline in yield as compared to the indicator. In other words, this suggests that we expect a decline in yield only to $84 \%$ if this plot is fertilized according to common practice and that this decline is mainly caused by the decrease in soil organic matter as a consequence of the management during the past decades. This seems to be plausible and, hence, we think that our concept provides useful results.

\subsection{C-storage Function}

The potential of the Bad Lauchstädt soil for carbon storage in association with fine particles is calculated to be $18.0 \mathrm{mg} / \mathrm{g}$ (Equation 10). Due to the fraction of particles $<20 \mu \mathrm{m}(52.4 \%)$, this leads the relative potential of the Bad Lauchstädt soil to store stable carbon to be $I_{\mathrm{SOC}}=0.59$ (Equation 12). The actual state for the different experimental plots fulfills this potential to very different degrees reflecting the different fertilizing regimes. While in the non-fertilized plot the potential for $\mathrm{C}$ storage is reached only by a factor of 0.65 (Equation 14), it is considerably higher for the plots that received either mineral fertilizer or manure $(0.75$ and 0.95 , respectively) and is completely reached in the plot that received mineral fertilizer plus manure (1.04). Again, it has to be considered that the chosen approach quantifies the potential for C stabilization associated with fine particles and not the total $\mathrm{C}$ storage. Experimental results from Bad Lauchstädt show that $\mathrm{C}$ storage in the plots with high addition of organic material is still increasing (unpublished data).

\subsection{Water Storage}

As already mentioned for the production function, the bulk density of all plots is somewhat higher as compared to the suggested optimal value for this silt loam soil $\left(1.3 \mathrm{~g} / \mathrm{cm}^{3}\right)$. Since the field is not inclined, the water capacity was measured by the total porosity calculated from the measured bulk density and assuming a particle density of $2.65 \mathrm{~g} / \mathrm{cm}^{3}$. Because of the elevated bulk density, the score for water storage $I_{\text {water storage }}$ was slightly below 1.0 for all plots.

\section{DISCUSSION}

\subsection{General Concept}

Our approach to evaluate soil functions is in line with other concepts that have been developed during the last three decades (Doran and Parkin, 1994; Karlen et al., 2003; Mueller et al., 2007). One common line is the identification of suitable and observable indicators that are related to the soil function to be evaluated and to use such indicators as proxies for soil functions. Another common feature is the use of scoring functions to map indicator values to a dimensionless scale reflecting their contribution with respect to the considered soil function, which allows the combination of a variety of relevant indicators.

The approach suggested in this paper was motivated by the wish to clearly distinguish between the intrinsic potential of some soil to provide various soil functions and its actual state, as recently suggested by Bünemann et al. (2018). This opens a clear perspective to come up with local options for actions toward sustainable management. This discrimination also leads to a clear identification of different types of soil properties (i.e., inherent 
vs. manageable) and provides a clear structure of what needs to be considered for modeling the dynamics of soil functions in response to soil management. Another motivation was to evaluate the various soil functions separately. In contrast to a general soil quality index, this allows for a differentiated analysis and a balancing between the different functions which are not necessarily synergistic. Moreover, the focus on individual soil functions can be based on more specific indicators so that the choice of soil properties used as indicator variables to quantify these functions can be more targeted.

At present, the proposed approach is in a conceptual stage and not yet fully developed for the entire spectrum of soil functions. For some of the soil functions it is not obvious what the most sensitive indicators should be. This is true for nutrient cycling having many different aspects (reactivity, sorption, buffering) depending on which nutrients are considered. For the habitat function, it is even not obvious what should be addressed, i.e., the diversity of the gene pool or the functional diversity of organisms, let alone the suitable indicators that could provide useful information. This is why we demonstrated the proposed approach in more detail only for those soil functions for which the current knowledge provides more solid grounds. It should be noted, however, that the proposed parametrizations of the various scoring functions are far from being rigorously tested (if this will be ever possible). They merely reflect our current understanding and certainly need to be adapted to different climatic regions, cropping systems or even soil types. However, this is not necessarily a shortcoming. In contrast, this provides the required flexibility to optimize the general concept for local applications. Overall, we believe that the proposed concept will be useful in the future. Our knowledge on soil processes is steadily growing, and this concept provides a framework where new insight can easily be included.

\subsection{Implications for Modeling}

Besides the evaluation of soils' potential and their actual state with respect to different functions, it is one of the most critical challenges in soil science today to understand the stability and resilience of soil functions and how they change in response to external forcing (e.g., through agriculture or climate change). The change in the state of soil functions can be assessed by evaluating time series of the related manageable attributes. Another important aspect is to identify critical thresholds in terms of forcing beyond which irreversible changes are expected. This has been investigated for example for critical mechanical loads that lead to irreversible soil compaction as a function of some critical water content in dependence of soil texture (Keller et al., 2012). Other examples, though less well understood, are how to reduce soil compaction through adaption of tillage and crop rotation or how to substantially increase stable soil organic matter by suitable management practices.

The key question is, are we able to model the dynamics of soil functions in response to external perturbations in quantitative terms? The previous analysis of how to evaluate the soil functions and especially their actual state provides a valuable basis for the development of the required models. In Table 1, the relevant soil attributes are listed for each soil function, separating inherent soil properties and those which are sensitive to soil management. Modeling the dynamics of an individual soil function needs to address the dynamics of all manageable soil attributes (marked green in Table 1) under the condition of the inherent soil properties. This implies that any model approach needs to be site-specific as, for example, the impact of tillage practices or the application of manure is different for different soil types and soil textures. Such a systemic model concept was recently suggested by Vogel et al. (2018).

An illustrative example is the dynamics of soil organic matter. To model the change in SOC stocks in response to some measures of soil management such as the quantity and quality of $\mathrm{C}$ inputs or the choice of the tillage system it is not sufficient to know the actual carbon content and the actual carbon saturation (Equation 14). Based on our current understanding and indicated in Table 1, we also need to address soil structural properties and their temporal dynamics induced by bioturbation and tillage. Earthworms enclose organic matter within relatively compacted casts, and in doing so, they protect organic matter from rapid decomposition and bring it in close connection to mineral surfaces for increased stabilization. In contrast, soil tillage tends to break open existing structures and expose stable carbon to further decomposition. Such feedback processes are currently not considered in classical soil carbon models (Dignac et al., 2017). For the other soil functions, the required modeling of their dynamics can be done analogously while the blueprint which soil attributes need to be considered is provided by the analysis of how to evaluate the soil's potential and its current state. This may open the possibility to come up with a scientifically sound impact assessment for selected practices of agricultural soil management with respect to individual soil functions.

For the evaluation of soil functions, process-oriented modeling would allow for a more direct assessment. For example, production can be estimated based on various crop growth models (Martre et al., 2015) so that the soils' actual state with respect to the production function could be quantified in absolute values of yield. Moreover, the soils' potential could be defined by choosing some optimal values for all the manageable properties and modeling crop yields for an ensemble of representative weather scenarios. One advantage of such a modeling approach is that the models can be calibrated on available data sets from Long Term Field Sites, including the not optimally fertilized sites as in the example of Bad Lauchstädt. Another perspective is that the model results can be used as a quantitative base for the formulation of appropriate, crop- and site-specific scoring functions. A major deficiency is that the required systemic models including the required dynamics and feedbacks of soil processes and properties are not yet available (Vogel et al., 2018).

\subsection{Data Requirements}

Once the required set of indicators and suitable scoring schemes for the evaluation of the single soil functions are identified, a crucial question is where to get the required data. The evaluation of soils potential for the various soil functions is based on inherent soil properties and site conditions (Table 1), which are typically available from classical soil profile descriptions and from meteorological data bases. The evaluation of the soils actual state 
is in most cases a local problem, and a typical question of farmers is, what is the state of my field with respect to its potential? In addition to the inherent soil properties, this evaluation is based on soil attributes that are affected by soil management, which needs to be addressed locally. In principle, this can be done at each location; however, it would be helpful to develop standardized protocols for both lab and field measurements or estimations of texture, bulk density, macro porosity, $\mathrm{pH}$, SOC, biodiversity and abundance of organisms (Schindelbeck et al., 2008). Ideally, this type of analysis should be doable by each farmer on his field. For some properties, as e.g., the characterization of soil structure in the field, no clear protocols exist at all (Rabot et al., 2018) and new approaches are required along these lines. In principle, however, the estimation of all attributes that are suggested here to evaluate the actual state of soil with respect to the different functions is possible. In doing so, it is possible to directly identify which soil function is critically below its optimum and, moreover, which are the soil attributes that could be improved by appropriate soil management to most efficiently improve this function. For example, the production function of the soil in Bad Lauchstädt could be increased by decreasing the soil bulk density in the fully fertilized plot and by increasing the soil organic matter content in the nonfertilized plot. Another advantage of the assessment of the individual soil functions is that decision makers can make sitespecific decisions on which soil function is most valuable to be optimized, i.e., whether optimization is aimed at productivity, nitrate reduction in groundwater, carbon storage or the quality of soil as habitat for organisms.

For some applications, the evaluation of soils potentials is required at the scale of landscapes, for example to support decision-making in landscape planning and to address the question of which soil function we lose when abandoning soils in a certain area in favor of some other purpose. In this case, the information on inherent soil properties (marked yellow in Table 1) should ideally be obtained from soil maps. However, available soil maps typically provide some characteristic soil types for each mapping unit and, hence, provide somewhat fuzzy information for specific locations. A rough estimation of the spatial distribution of soil functions within landscapes should nonetheless be possible. In any case, the proposed approach allows translating the uncertainties in soil information to uncertainties in the evaluation of soil functions. For example, if we know the confidence limits of soil texture analysis this can be directly translated to confidence limits for $\mathrm{C}$ storage potential (Equation 12), water storage (Equation 8) or the rating of the production function (Equation 4). This also demonstrates the advantage of continuous scoring functions as compared to discrete classified scores.

To further develop scoring functions and to validate concepts to evaluate soil functions, highly valuable data are provided by long-term agricultural field experiments and other long-term soil monitoring sites. They also allow evaluating the dynamics of the state of soil functions in response to soil management and variations in climate.

\section{CONCLUSIONS}

Building upon existing concepts for the evaluation of soil functions, we propose an approach to quantitatively evaluate soil functions while separating the intrinsic potential of soil and its actual state. This is done for each function separately so that the different contributions of a given soil to the individual soil functions can be accounted for. The concept is demonstrated for those functions where appropriate indicator variables are already well established (i.e., production, C storage and water storage). While the concept of using dimensionless scoring functions seems to be generally useful, we conclude that the parametrization of these functions needs more comprehensive data bases, especially since it needs to be sensitive to site conditions, crops and cropping systems. There are indicator variables such as soil structure including its stability and temporal dynamics, which are known to be essential for various soil functions but difficult to quantify. For other important soil functions the formulation of evaluation schemes still needs to be done. This is true for nutrient cycling due to the complexity of interacting processes and for the habitat function, which is still not clearly defined, and suitable indicators are missing. However, we believe that the presented approach is generally useful and can provide valuable input to modeling soil functions since it provides a blueprint of the type of soil variables and their interactions, which should be represented by some systemic modeling of the dynamics of soil functions.

\section{DATA AVAILABILITY STATEMENT}

All datasets generated for this study are included in the manuscript/supplementary files.

\section{AUTHOR CONTRIBUTIONS}

H-JV and UWo developed the concept of the presented approach. EE provided contributions to link the evaluation approach to available soil data handling. UF provided data and interpretation for the long-term field experiment in Bad Lauchstädt and contributed to the formulation of the scoring functions. BL reviewed literature on the habitat function of soil and wrote the corresponding text. ML critically reviewed the manuscript and improved the consistency. MW reviewed literature on the $\mathrm{C}$ storage function and wrote the corresponding text. UWe provided some links to modeling.

\section{FUNDING}

This work was funded by the German Federal Ministry of Education and Research (BMBF) in the framework of the funding measure Soil as a Sustainable Resource for the Bioeconomy BonaRes, project BonaRes (Module B): BonaRes Centre for Soil Research (grant 031B0511). For further information please visit www.bonares.de. 


\section{REFERENCES}

Ad-hoc-AG Boden (2005). Bodenkundliche Kartieranleitung, 5th Edn. Hanover: Schweizerbart (in Komm.).

Aksoy, E., Louwagie, G., Gardi, C., Gregor, M., Schröder, C., and Löhnertz, M. (2017). Assessing soil biodiversity potentials in Europe. Sci. Tot. Environ. 589, 236-249. doi: 10.1016/j.scitotenv.2017.02.173

Allen, R., Pereira, L., Raes, D., and Smith, M. (1998). Crop-Evapotranspiration - Guidelines for Computing Crop Water Requirements - FAO Irrigation and Drainage Paper 56. Technical report, FAO - Food and Agriculture Organization of the United Nations.

Andrews, S. S., Karlen, D. L., and Cambardella, C. A. (2004). The soil management assessment framework. Soil Sci. Soc. Am. J. 68, 1945-1962. doi: 10.2136/sssaj2004.1945

Angers, D., Arrouays, D., Saby, N., and Walter, C. (2011). Estimating and mapping the carbon saturation deficit of french agricultural topsoils. Soil Use Manag. 27, 448-452. doi: 10.1111/j.1475-2743.2011.00366.x

Arrouays, D., Saby, N., Walter, C., Lemercier, B., and Schvartz, C. (2006). Relationships between particle-size distribution and organic carbon in french arable topsoils. Soil Use Manag. 22, 48-51. doi: $10.1111 / j .1475-2743.2006 .00020 . x$

Bardgett, R. D., and Van Der Putten, W. H. (2014). Belowground biodiversity and ecosystem functioning. Nature 515:505. doi: 10.1038/nature13855

Barré, P., Durand, H., Chenu, C., Meunier, P., Montagne, D., Castel, G., et al. (2017). Geological control of soil organic carbon and nitrogen stocks at the landscape scale. Geoderma 285, 50-56. doi: 10.1016/j.geoderma.2016.09.029

Baveye, P. C., Baveye, J., and Gowdy, J. (2016). Soil-ecosystem-services and natural capital: critical appraisal of research on uncertain ground. Front. Environ. Sci. 4:41. doi: 10.3389/fenvs.2016.00041

Beare, M., McNeill, S., Curtin, D., Parfitt, R., Jones, H., Dodd, M., et al. (2014). Estimating the organic carbon stabilisation capacity and saturation deficit of soils: a New Zealand case study. Biogeochemistry 120, 71-87. doi: 10.1007/s10533-014-9982-1

Bispo, A., Cluzeau, D., Creamer, R., Dombos, M., Graefe, U., Krogh, P. H., et al. (2009). Indicators for monitoring soil biodiversity. Integr. Environ. Assess. Manage. 5, 717-719. doi: 10.1897/IEAM-2009-064.1

Blum, W. (2005). Soils and climate change. J. Soils Sediments 5, 67-68. doi: $10.1065 /$ jss 2005.02 .006

Bouma, J. (2014). Soil science contributions towards sustainable development goals and their implementation: linking soil functions with ecosystem services. J. Plant Nutr. Soil Sci. 177, 111-120. doi: 10.1002/jpln.201300646

Bouma, J., and Montanarella, L. (2016). Facing policy challenges with inter- and transdisciplinary soil research focused on the un sustainable development goals. Soil 2, 135-145. doi: 10.5194/soil-2-135-2016

Bünemann, E. K., Bongiorno, G., Bai, Z., Creamer, R. E., Deyn, G. D., de Goede, R., et al. (2018). Soil quality - a critical review. Soil Biol. Biochem. 120, 105-125. doi: 10.1016/j.soilbio.2018.01.030

Burkhardt, U., Russell, D., Decker, P., Döhler, M., Höfer, H., Lesch, S., et al. (2014). The edaphobase project of gbif-germany - a new online soil-zoological data warehouse. Appl. Soil Ecol. 83, 3-12. doi: 10.1016/j.apsoil.2014.03.021

Calzolari, C., Ungaro, F., Filippi, N., Guermandi, M., Malucelli, F., Marchi, N., et al. (2016). A methodological framework to assess the multiple contributions of soils to ecosystem services delivery at regional scale. Geoderma 261, 190-203. doi: 10.1016/j.geoderma.2015.07.013

Carter, M., Angers, D., Gregorich, E., and Bolinder, M. (2003). Characterizing organic matter retention for surface soils in Eastern Canada using density and particle size fractions. Can. J. Soil Sci. 83, 11-23. doi: 10.4141/S01-087

Chan, K. (2001). Soil particulate organic carbon under different land use and management. Soil Use Manag. 17, 217-221. doi: 10.1079/SUM200180

Chen, S., Arrouays, D., Angers, D. A., Chenu, C., Barré, P., Martin, M. P., et al. (2019a). National estimation of soil organic carbon storage potential for arable soils: A data-driven approach coupled with carbon-landscape zones. Sci. Tot. Environ. 666, 355-367. doi: 10.1016/j.scitotenv.2019.02.249

Chen, S., Arrouays, D., Angers, D. A., Martin, M. P., and Walter, C. (2019b). Soil carbon stocks under different land uses and the applicability of the soil carbon saturation concept. Soil Tillage Res. 188, 53-58. doi: 10.1016/j.still.2018.11.001

Chen, S., Martin, M. P., Saby, N. P., Walter, C., Angers, D. A., and Arrouays, D. (2018). Fine resolution map of top-and subsoil carbon sequestration potential in France. Sci. Tot. Environ. 630, 389-400. doi: 10.1016/j.scitotenv.2018.02.209
Cluzeau, D., Guernion, M., Chaussod, R., Martin-Laurent, F., Villenave, C., Cortet, J., et al. (2012). Integration of biodiversity in soil quality monitoring: baselines for microbial and soil fauna parameters for different land-use types. Eur. J. Soil Biol. 49, 63-72. doi: 10.1016/j.ejsobi.2011.11.003

Conant, R. T., Six, J., and Paustian, K. (2003). Land use effects on soil carbon fractions in the Southeastern United States. I. Managementintensive versus extensive grazing. Biol. Fertil. Soils 38, 386-392. doi: 10.1007/s00374-003-0652-z

Costanza, R., d'Arge, R., De Groot, R., Farber, S., Grasso, M., Hannon, B., et al. (1997). The value of the world's ecosystem services and natural capital. Nature 387:253. doi: 10.1038/387253a0

Danner, C., Hensold, C., Blum, P., Wiedenhammer, S., Außendorf, M., Kraft, M., et al. (2003). Das Schutzgut Boden in der Planung. Technical report, Bayerisches Geologisches Landesamt and Bayerisches Landesamt für Umweltschutz.

Decaëns, T. (2010). Macroecological patterns in soil communities. Glob. Ecol. Biogeogr. 19, 287-302. doi: 10.1111/j.1466-8238.2009.00517.x

Di, J., Feng, W., Zhang, W., Cai, A., and Xu, M. (2017). Soil organic carbon saturation deficit under primary agricultural managements across major croplands in China. Ecosyst. Health Sustain. 3:1364047. doi: 10.1080/20964129.2017.1364047

Dignac, M.-F., Derrien, D., Barré, P., Barot, S., Cécillon, L., Chenu, C., et al. (2017). Increasing soil carbon storage: mechanisms, effects of agricultural practices and proxies. A review. Agron. Sustain. Dev. 37:14. doi: 10.1007/s13593-017-0421-2

Dominati, E., Patterson, M., and Mackay, A. (2010). A framework for classifying and quantifying the natural capital and ecosystem services of soils. Ecol. Econ. 69, 1858-1868. doi: 10.1016/j.ecolecon.2010.05.002

Doran, J. W., and Parkin, T. B. (1994). "Defining soil quality for a sustainable environment," in Biological Indicators of Soil Health, eds C. Pankhurst, B. Doube, and V. Gupta (Wallingford: CAB International), 1-28.

Feng, W., Plante, A. F., and Six, J. (2013). Improving estimates of maximal organic carbon stabilization by fine soil particles. Biogeochemistry 112, 81-93. doi: 10.1007/s10533-011-9679-7

Greiner, L., Keller, A., Grêt-Regamey, A., and Papritz, A. (2017). Soil function assessment: review of methods for quantifying the contributions of soils to ecosystem services. Land Use Policy 69, 224-237. doi: 10.1016/j.landusepol.2017.06.025

Griffiths, R. I., Thomson, B. C., Plassart, P., Gweon, H. S., Stone, D., Creamer, R. E., et al. (2016). Mapping and validating predictions of soil bacterial biodiversity using European and national scale datasets. Appl. Soil Ecol. 97, 61-68. doi: 10.1016/j.apsoil.2015.06.018

Hassink, J. (1997). The capacity of soils to preserve organic C and N by their association with clay and silt particles. Plant Soil 191, 77-87. doi: 10.1023/A:1004213929699

Hauck, J., Görg, C., Varjopuro, R., Ratamäki, O., and Jax, K. (2013). Benefits and limitations of the ecosystem services concept in environmental policy and decision making: some stakeholder perspectives. Environ. Sci. Policy 25, 13-21. doi: 10.1016/j.envsci.2012.08.001

Hooper, D. U., Chapin, F. S., Ewel, J. J., Hector, A., Inchausti, P., Lavorel, S., et al. (2005). Effects of biodiversity on ecosystem functioning: a consensus of current knowledge. Ecol. Monogr. 75, 3-35. doi: 10.1890/04-0922

Huber, S., Prokop, G., Arrouays, D., Banko, G., Bispo, A., Jones, R., et al. (2008). Environmental Assessment of Soil for Monitoring: Volume I, Indicators \& Criteria. Luxembourg: Office for the Official Publications of the European Communities.

Jenny, H. (1941). Factors of Soil Formation. New York, NY: McGraw-Hill Book Co. Johannes, A., Matter, A., Schulin, R., Weisskopf, P., Baveye, P. C., and Boivin, P. (2017). Optimal organic carbon values for soil structure quality of arable soils. Does clay content matter? Geoderma 302, 14-21. doi: 10.1016/j.geoderma.2017.04.021

Karlen, D., Mausbach, M. J., Doran, J., Cline, R., Harris, R., and Schuman, G. (1997). Soil quality: a concept, definition, and framework for evaluation (a guest editorial). Soil Sci. Soc. Am. J. 61, 4-10. doi: 10.2136/sssaj1997.03615995006100010001x

Karlen, D. L., Ditzler, C. A., and Andrews, S. S. (2003). Soil quality: why and how? Geoderma 114, 145-156. doi: 10.1016/S0016-7061(03)00039-9

Keesstra, S. D., Quinton, J. N., van der Putten, W. H., Bardgett, R. D., and Fresco, L. O. (2016). The significance of soils and soil science towards realization of the United Nations sustainable development goals. Soil 2:111. doi: 10.5194/soil-2-111-2016 
Keller, T., Arvidsson, J., Schjønning, P., Lamandé, M., Stettler, M., and Weisskopf, P. (2012). In situ subsoil stress-strain behavior in relation to soil precompression stress. Soil Sci. 177, 490-497. doi: 10.1097/SS.0b013e318262554e

Kibblewhite, M., Ritz, K., and Swift, M. (2008). Soil health in agricultural systems. Philos. Trans. R. Soc. Lond. B Biol. Sci. 363, 685-701. doi: $10.1098 /$ rstb.2007.2178

Lal, R. (2018). Digging deeper: A holistic perspective of factors affecting soil organic carbon sequestration in agroecosystems. Glob. Change Biol. 24, 32853301. doi: $10.1111 /$ gcb. 14054

Larson, W. E., and Pierce, F. J. (1994). "The dynamics of soil quality as a measure of sustainable management," in Defining Soil Quality for a Sustainable Environment, eds J. W. Doran, D. C. Coleman, D. F. Bezdicek, and B. A. Stewart (Madison, WI: Soil Science Society of America and American Society of Agronomy), 37-51.

Martre, P., Wallach, D., Asseng, S., Ewert, F., Jones, J. W., Rötter, R. P., et al. (2015). Multimodel ensembles of wheat growth: many models are better than one. Global Change Biol. 21, 911-925. doi: 10.1111/gcb.12768

McBratney, A., Field, D. J., and Koch, A. (2014). The dimensions of soil security. Geoderma 213, 203-213. doi: 10.1016/j.geoderma.2013.08.013

Moebius-Clune, B. N. (2017). Comprehensive Assessment of Soil Health: The Cornell Framework Manual. Ithaca, NY: Cornell University.

Mueller, L., Schindler, U., Behrendt, A., Eulenstein, F., and Dannowski, R. (2007). The Muencheberg Soil Quality Rating (SQR) - Field Manual for Detecting and Assessing Properties and Limitations of Soils for Cropping and Grazing. Technical report, Leibniz-Centre for Agricultural Landscape Research (ZALF) e. V., Muencheberg.

Orgiazzi, A., Ballabio, C., Panagos, P., Jones, A., and Fernańdez-Ugalde, O. (2018). Lucas soil, the largest expandable soil dataset for europe: a review. Eur. J. Soil Sci. 69, 140-153. doi: 10.1111/ejss.12499

Parisi, V., Menta, C., Gardi, C., Jacomini, C., and Mozzanica, E. (2005). Microarthropod communities as a tool to assess soil quality and biodiversity: a new approach in Italy. Agricult. Ecosyst. Environ. 105, 323-333. doi: 10.1016/j.agee.2004.02.002

Pulleman, M., Creamer, R., Hamer, U., Helder, J., Pelosi, C., Peres, G., et al. (2012). Soil biodiversity, biological indicators and soil ecosystem services - an overview of European approaches. Curr. Opin. Environ. Sustain. 4, 529-538. doi: 10.1016/j.cosust.2012.10.009

Rabot, E., Wiesmeier, M., Schlüter, S., and Vogel, H.-J. (2018). Soil structure as an indicator of soil functions: a review. Geoderma 314, 122-137. doi: 10.1016/j.geoderma.2017.11.009

Robinson, D. A., Lebron, I., and Vereecken, H. (2009). On the definition of the natural capital of soils: a framework for description, evaluation, and monitoring. Soil Sci. Soc. Am. J. 73, 1904-1911. doi: 10.2136/sssaj2008.0332

Rumpel, C. and Kögel-Knabner, I. (2011). Deep soil organic matter - a key but poorly understood component of terrestrial C cycle. Plant Soil 338, 143-158. doi: 10.1007/s11104-010-0391-5

Rutgers, M., Orgiazzi, A., Gardi, C., Römbke, J., Jänsch, S., Keith, A. M., et al. (2016). Mapping earthworm communities in Europe. Appl. Soil Ecol. 97, 98-111. doi: 10.1016/j.apsoil.2015.08.015

Rutgers, M., van Leeuwen, J. P., Vrebos, D., van Wijnen, H. J., Schouten, T., and de Goede, R. G. (2019). Mapping soil biodiversity in Europe and the Netherlands. Soil Syst. 3, 1-17. doi: 10.3390/soilsystems3020039

Sabais, A. C. W., Scheu, S., and Eisenhauer, N. (2011). Plant species richness drives the density and diversity of Collembola in temperate grassland. Acta Oecol. 37, 195-202. doi: 10.1016/j.actao.2011.02.002

Sánchez-Moreno, S., Ferris, H., Young-Mathews, A., Culman, S. W., and Jackson, L. E. (2011). Abundance, diversity and connectance of soil food web channels along environmental gradients in an agricultural landscape. Soil Biol. Biochem. 43, 2374-2383. doi: 10.1016/j.soilbio.2011.07.016

Scheunemann, N., Maraun, M., Scheu, S., and Butenschoen, O. (2015). The role of shoot residues vs. crop species for soil arthropod diversity and abundance of arable systems. Soil Biol. Biochem. 81, 81-88. doi: 10.1016/j.soilbio.2014.11.006

Schindelbeck, R. R., van Es, H. M., Abawi, G. S., Wolfe, D. W., Whitlow, T. L., Gugino, B. K., et al. (2008). Comprehensive assessment of soil quality for landscape and urban management. Landsc. Urban Plan. 88, 73-80. doi: 10.1016/j.landurbplan.2008.08.006

Schulte, R. P., Bampa, F., Bardy, M., Coyle, C., Creamer, R. E., Fealy, R., et al. (2015). Making the most of our land: managing soil functions from local to continental scale. Front. Environ. Sci. 3:81. doi: 10.3389/fenvs.2015.00081
Schulte, R. P., Creamer, R. E., Donnellan, T., Farrelly, N., Fealy, R., O’Donoghue, C., et al. (2014). Functional land management: a framework for managing soil-based ecosystem services for the sustainable intensification of agriculture. Environ. Sci. Policy 38, 45-58. doi: 10.1016/j.envsci.2013. 10.002

Six, J., Conant, R., Paul, E. A., and Paustian, K. (2002). Stabilization mechanisms of soil organic matter: implications for C-saturation of soils. Plant soil 241, 155-176. doi: 10.1023/A:1016125726789

Sojka, R., and Upchurch, D. (1999). Reservations regarding the soil quality concept. Soil Sci. Soc. Am. J. 63, 1039-1054. doi: 10.2136/sssaj1999.6351039x

Spangenberg, J. H., Görg, C., Truong, D. T., Tekken, V., Bustamante, J. V., and Settele, J. (2014). Provision of ecosystem services is determined by human agency, not ecosystem functions. Four case studies. Int. J. Biodivers. Sci. Ecosyst. Serv. Manag. 10, 40-53. doi: 10.1080/21513732.2014.884166

Sparrow, L., Belbin, K., and Doyle, R. (2006). Organic carbon in the silt + clay fraction of tasmanian soils. Soil Use Manag. 22, 219-220. doi: 10.1111/j.1475-2743.2006.00021.x

Staes, J., Vrebos, D., Georgoulas, A., Meire, P., Jones, A., Creamer, R., et al. (2018). Demand Scenarios: Quantification of the Demand for Soil Functions. LANDMARK report 4.1. Available online at: https://landmark2020.eu/

Stewart, C. E., Paustian, K., Conant, R. T., Plante, A. F., and Six, J. (2008). Soil carbon saturation: evaluation and corroboration by long-term incubations. Soil Biol. Biochem. 40, 1741-1750. doi: 10.1016/j.soilbio.2008.02.014

Tsiafouli, M. A., Thébault, E., Sgardelis, S. P., De Ruiter, P. C., Van Der Putten, W. H., Birkhofer, K., et al. (2015). Intensive agriculture reduces soil biodiversity across Europe. Glob. Change Biol. 21, 973-985. doi: 10.1111/gcb.12752

Turbé, A., De Toni, A., Benito, P., Lavelle, P., Lavelle, P., Camacho, N. R., et al. (2010). Soil Biodiversity: Functions, Threats and Tools for Policy Makers. European Commission - DG ENV.

van Capelle, C., Schrader, S., and Brunotte, J. (2012). Tillage-induced changes in the functional diversity of soil biota-a review with a focus on German data. Eur. J. Soil Biol. 50, 165-181. doi: 10.1016/j.ejsobi.2012.02.005

Vogel, H.-J., Bartke, S., Daedlow, K., Helming, K., Kögel-Knabner, I., Lang, B., et al. (2018). A systemic approach for modeling soil functions. Soil 4, 83-92. doi: 10.5194/soil-4-83-2018

von Lützow, M., Kögel-Knabner, I., Ekschmitt, K., Matzner, E., Guggenberger, G., Marschner, B., et al. (2006). Stabilization of organic matter in temperate soils: mechanisms and their relevance under different soil conditions-a review. Eur. J. Soil Sci. 57, 426-445. doi: 10.1111/j.1365-2389.2006.00809.x

Wiesmeier, M., Hübner, R., Spörlein, P., Geuß, U., Hangen, E., Reischl, A., et al. (2014a). Carbon sequestration potential of soils in Southeast Germany derived from stable soil organic carbon saturation. Glob. Change Biol. 20, 653-665. doi: $10.1111 /$ gcb.12384

Wiesmeier, M., Munro, S., Barthold, F., Steffens, M., Schad, P., and KögelKnabner, I. (2015). Carbon storage capacity of semi-arid grassland soils and sequestration potentials in Northern China. Glob. Change Biol. 21, 3836-3845. doi: $10.1111 /$ gcb.12957

Wiesmeier, M., Schad, P., von Lützow, M., Poeplau, C., Spörlein, P., Geuß, U., et al. (2014b). Quantification of functional soil organic carbon pools for major soil units and land uses in Southeast Germany (Bavaria). Agricult. Ecosyst. Environ. 185, 208-220. doi: 10.1016/j.agee.2013.12.028

Wiesmeier, M., Urbanski, L., Hobley, E., Lang, B., von Lützow, M., Marin-Spiotta, E., et al. (2019). Soil organic carbon storage as a key function of soils - a review of drivers and indicators at various scales. Geoderma 333, 149-162. doi: 10.1016/j.geoderma.2018.07.026

Zhao, L., Sun, Y., Zhang, X., Yang, X., and Drury, C. (2006). Soil organic carbon in clay and silt sized particles in Chinese mollisols: relationship to the predicted capacity. Geoderma 132, 315-323. doi: 10.1016/j.geoderma.2005.04.026

Conflict of Interest: The authors declare that the research was conducted in the absence of any commercial or financial relationships that could be construed as a potential conflict of interest.

Copyright () 2019 Vogel, Eberhardt, Franko, Lang, Ließ, Weller, Wiesmeier and Wollschläger. This is an open-access article distributed under the terms of the Creative Commons Attribution License (CC BY). The use, distribution or reproduction in other forums is permitted, provided the original author(s) and the copyright owner(s) are credited and that the original publication in this journal is cited, in accordance with accepted academic practice. No use, distribution or reproduction is permitted which does not comply with these terms. 